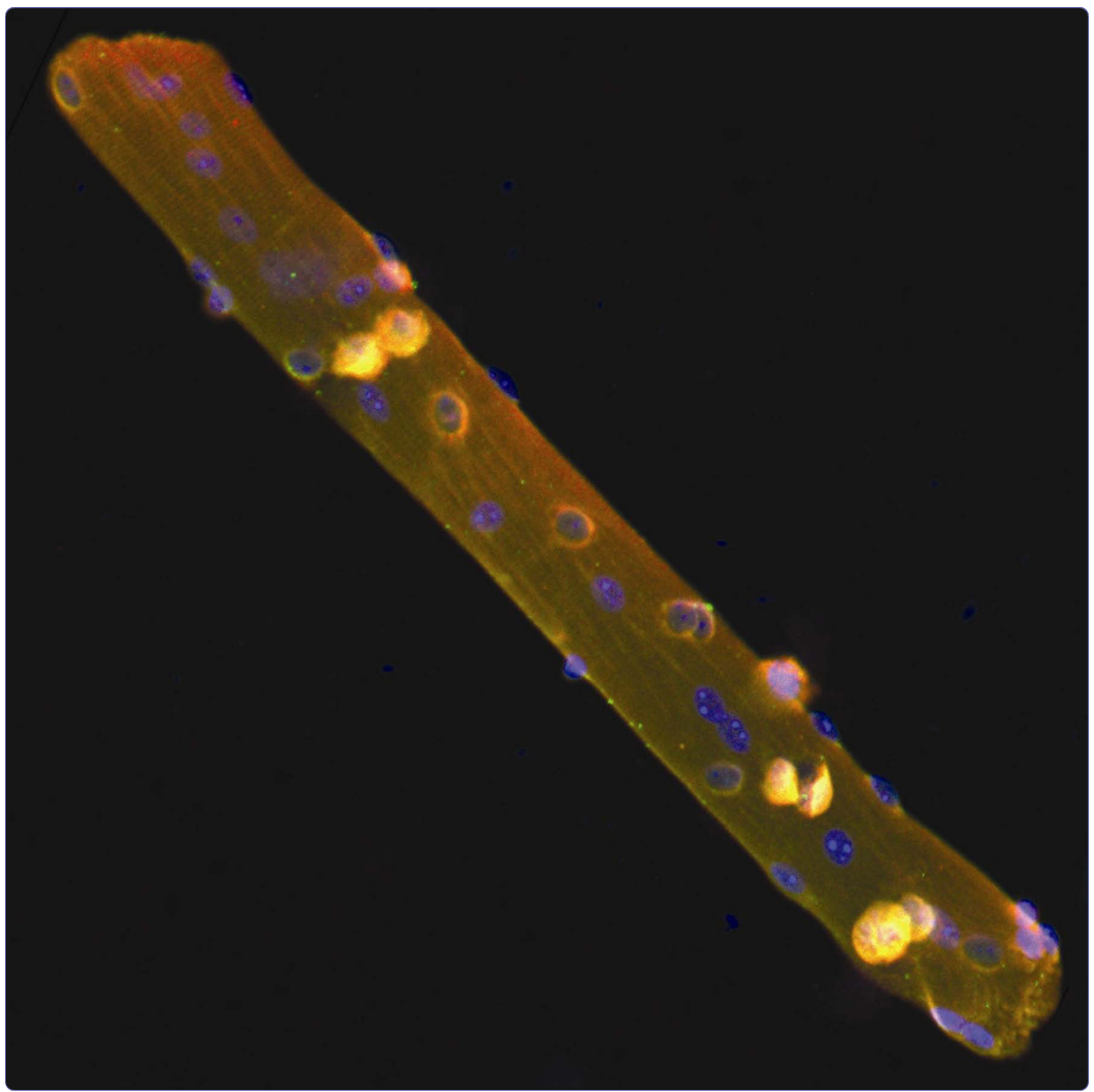

\title{
Extrinsic regulation of satellite cell specification
}

Bentzinger et al.

() Biomed Central 


\title{
Extrinsic regulation of satellite cell specification
}

\author{
C Florian Bentzinger', Julia von Maltzahn' and Michael A Rudnickil,2*
}

\begin{abstract}
Cellular commitment during vertebrate embryogenesis is controlled by an interplay of intrinsic regulators and morphogenetic signals. These mechanisms recruit a subset of cells in the developing organism to become the ancestors of skeletal muscle. Signals that control progression through the myogenic lineage converge on a battery of hierarchically organized transcription factors which modulate the cells to either remain in a primitive state or allow their commitment and differentiation into skeletal muscle fibers. A small population of cells will retain a largely unspecified state throughout development. Such stem cells, in conjunction with more committed myogenic progenitors, form a heterogeneous population that colonizes adult skeletal muscle as satellite cells. The satellite cell pool is responsible for the remarkable regenerative capacity of skeletal muscle. Similar to their counterparts during embryonic development, satellite cells are capable of self-renewal and can give rise to myogenic progeny. Impaired satellite cell homeostasis has been associated with numerous muscular disorders. Due to intense research efforts in the past two decades, the complex biology of muscle stem cells has now revealed some of its secrets and new avenues for the development of therapeutic molecules have emerged. In the present review we focus on the extrinsic mechanisms that control self-renewal, specification and differentiation of satellite cells and their significance for the development of biologic drugs.
\end{abstract}

\section{Introduction}

Myogenic specification initially takes place in the somites of the developing vertebrate embryo and is thenceforth reiterated throughout the life of the organism [1]. This

\footnotetext{
*Correspondence: mrudnicki@ohri.ca

'The Sprott Centre for Stem Cell Research, Regenerative Medicine Program,

Ottawa Health Research Institute, Ottawa, Ontario K1H 8L6, Canada

Full list of author information is available at the end of the article
}

process will establish and maintain one of the major constituents of the body: skeletal muscle. The presence of tissue-specific stem cells, the satellite cells, gives adult muscle the capacity for extensive regeneration in response to trauma and disease [2]. Despite a fundamentally different hormonal and anatomical environment, muscle regeneration in the adult organism recapitulates many aspects of embryonic myogenesis [3]. However, the capacity of adult muscle for regeneration seems to be limited and repeated degeneration is accompanied by increasingly inefficient tissue reconstitution [4]. Since the discovery of the satellite cell 50 years ago, research has provided valuable insights into the molecular mechanisms that regulate the satellite cell pool and ultimately the potential for regenerative myogenesis $[5,6]$. Particularly, a recently discovered subpopulation of satellite cells with an extensive capacity for self-renewal and the characterized signaling molecules that control these cells hold great potential for therapeutic manipulation $[7,8]$.

\section{Developmental myogenesis}

Skeletal muscle in all vertebrates originates from cells found in the mesoderm, one of the three primary germ layers $[9,10]$. Parts of the mesoderm give rise to segmented clusters called somites, which are aligned along the anterior-posterior axis of the embryo. The somites, the paraxial head mesoderm and the prechordal mesoderm are the source of primitive myogenic cells, most of which are marked by the expression of two paired-box (Pax) transcription factors, Pax3 and Pax7. Later during development, a subpopulation of these cells will differentiate into terminally committed myocytes. The embryonic body axes then orient the fusion of these cells, generating the first multinucleated myofibers. In several subsequent waves, more embryonic myocytes align and fuse into precisely arranged postmitotic muscle fibers that will give rise to the organism's skeletal muscle. Limb, trunk and some head muscles arise from cells of somitic origin, whereas the remainder of the head muscles derive from cells of the paraxial head mesoderm and the prechordal mesoderm [1,11-15].

Myogenic specification during development is regulated by signaling factors released from the surrounding tissue. Among such factors are sonic hedgehog (Shh), 
which is released from the neural tube, lateral mesoderm derived bone morphogenetic proteins (BMPs), and members of the wingless-type MMTV integration site (Wnt) family of proteins, which emanate from both the ectoderm and the neural tube [1]. On the genetic level, myogenic determination is modulated by Pax3/Pax7 and a family of transcription factors known as myogenic regulatory factors (MRFs) [6].

In the perinatal period, the niche in between the basal lamina and the muscle fiber membrane is populated by juvenile satellite cells that proliferate extensively. A subset of theses cells will remain as quiescent satellite cells in the adult organism [16].

\section{Satellite stem cells}

With the exception of some head muscles, satellite cells in the adult are generally considered to be the progeny of Pax3- and Pax7-expressing cells of somitic origin [1114,17]. Pax transcription factors are genetic master switches that can imprint stem cells towards a myogenic fate but repress genes involved in differentiation. All adult satellite cells are marked by the expression of Pax7 whereas Pax3 is postnatally downregulated in most muscles [18]. Other molecular markers of satellite cells include vascular cell adhesion molecule 1 (VCAM-1), c-Met (receptor for hepatocyte growth factor), chemokine C-X-C motif receptor 4 (CXCR4), M-cadherin, neural cell adhesion molecule 1 (NCAM1), forkhead box protein K1 (Foxk1), integrin $\alpha 7 \beta 1, \mathrm{CD} 34$, and syndecans 3 and 4 [19].

In adult skeletal muscle only a small subpopulation of Pax7-expressing satellite cells derives from a lineage that has never expressed myogenic factor 5 (Myf5), a transcription factor belonging to the MRFs. It has been demonstrated that these cells are capable of extensive self-renewal and can very efficiently repopulate their niche in transplantation experiments into satellite-celldepleted muscle. To date, this cell type makes up the most primitive and stem-like population that has been identified in adult muscle tissue and these cells are therefore referred to as 'satellite stem cells'. Conversely, a cell that expresses Myf5 or is descended from an ancestor that expressed this factor once is more prone to differentiation and is therefore termed a 'satellite myogenic cell' [7].

\section{Regenerative myogenesis}

Injury of adult muscle causes an influx of inflammatory cells that remove necrotic debris from the tissue. Subsequently, Pax7-expressing satellite cells enter mitosis to generate progeny that will go through repeated rounds of proliferation and then migrate to the site of damage. A high percentage of this progeny will undergo myogenic differentiation in order to restore the destroyed muscle fibers, whereas others will self-renew and, upon complete regeneration, repopulate the muscle as satellite stem cells [2].

Once activated by muscle injury, proliferating satellite cells become myoblasts through upregulation of a MRF called myoblast determination protein (MyoD) [18]. MyoD drives proliferation by controlling reentry into the cell cycle and activates the transcription of musclespecific genes [20]. As a last step, downregulation of Pax7 and upregulation of myogenin primes the myoblasts to become myocytes. These cells are terminally committed, exit the cell cycle and fuse with other myoblasts or existing fibers. This process will finally repair the damaged muscle tissue [6]. Satellite cell self-renewal and the transcription factors controlling lineage progression during regeneration are thought to be regulated by a variety of extrinsic cues [19]. For the remaining part of this review, we will focus on these factors.

\section{The satellite cell niche}

A stem cell niche is defined as a specific anatomical location that participates in tissue generation, maintenance and repair. Stem cells reside in their niche for an indefinite period and it protects its host from depletion or uncontrolled proliferation [21].

The satellite cell niche is exceptionally complex and the sources of environmental influences are diverse. For instance, satellite cells are often localized in close proximity to capillaries, which might be a means to efficiently supply them with signaling factors [22]. Furthermore, several cell types, such as fibroblasts and immune cells, can colonize muscle tissue. These cells secrete cytokines that may influence satellite cells [19]. Neural input leads to depolarization of the muscle fiber, which can affect satellite cells through paracrine factors and adhesion molecules [23,24].

The basement membrane and the muscle fiber sarcolemma, in-between which the satellite cell is wedged, are the main anatomical hallmarks of its niche. The function of the extracellular matrix (ECM) for satellite cells during myogenesis is a matter of ongoing investigation. It has been documented that certain ECM proteins like laminin and collagen are reciprocally regulated by fibronectin, hyaluronic acid and tenascin during muscle regeneration [25]. Fibronectin inhibits the differentiation of cultured myoblasts whereas laminin promotes it [26,27]. Mice suffering from muscular dystrophy, which is caused by a null mutation in the laminin alpha 2 chain, display dramatic defects in muscle regeneration [28]. Furthermore, knockout of the matrix modifying enzyme membrane type 1 metalloprotease (MT1-MMP) in mice results in impaired skeletal muscle recovery after injury [29]. This evidence demonstrates that an intact ECM is essential for muscle repair and suggests that transitional changes in its composition 

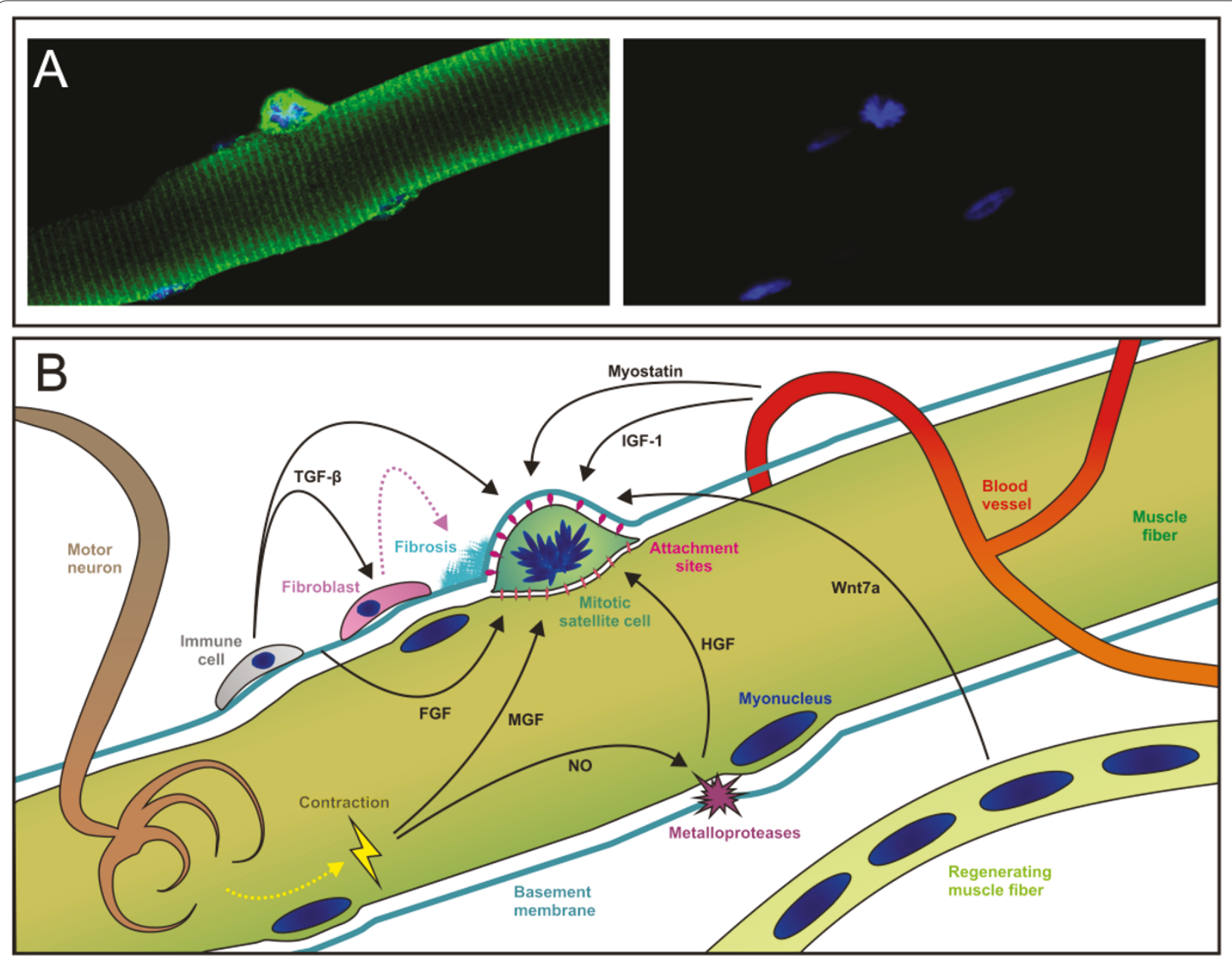

Figure 1. The satellite cell niche and regulatory factors. (a) Fluorescence microscopic image of a mitotic satellite cell (metaphase) on a mouse muscle fiber. The satellite cell is labeled by the expression of a yellow fluorescent protein and DNA is stained in blue. (b) Schematic of the different environmental cues influencing a satellite cell in its niche. FGF, fibroblast growth factor; HGF, hepatocyte growth factor; IGF, insulin-like growth factor; MGF, mechano-growth factor; NO, nitric oxide; TGF, transforming growth factor.

provide instructive cues to satellite cells. Next to its structural composition, the niche controls satellite cells through several signaling molecules that emanate from a wide range of sources (Figure 1).

\section{Signaling factors regulating satellite cells}

The amount of satellite cells decreases with age, although their myogenic potential does not diminish throughout the life of the organism [30]. This notion has been supported by experiments demonstrating a significant myogenic capacity of satellite cells transplanted from old tissue into young muscle. On the other hand, when young cells were transplanted into old muscle, they did not perform well [31,32]. Furthermore, exposure of old mice to serum from young mice dramatically improved their regenerative capacity [33]. Taken together, this evidence indicates that satellite cells are highly regulated by extrinsic cues. The identification and understanding of these factors will open new avenues for the development of therapeutic strategies. Drugs with the ability to increase or restore the regenerative potential of skeletal muscle by boosting satellite cell function or number could help to preserve muscle mass in degenerative muscular disorders.

\section{Development of biologics for therapeutic manipulation of satellite cells}

Satellite stem cell transplantation could theoretically be a promising approach to restore or enhance the regenerative potential of diseased muscle. In reality, such cellbased approaches face serious limitations, including the need to cultivate satellite cells, their incompatibility with systemic delivery, and their poor survival following intramuscular injection [34]. For these reasons, 
alternative approaches need to be taken into consideration. The existence of numerous physiological factors that are involved in the regulation of satellite cells provides an opportunity for the development of drugs that mimic or interfere with these molecules [18].

Biologic drugs are pharmaceuticals inherently biological in nature and manufactured using biotechnology [35]. The advantages of biologics over classic small molecular compounds are that they harness the same principles employed by endogenous proteins: high functional specificity resulting in a well defined biological effect with little or no off-target activity [36]. In the following sections we discuss some approaches for the rational design of biologics mimicking or inhibiting signaling molecules that control satellite cell function.

\section{Transforming growth factor- $\beta$}

An impaired regenerative capacity and chronic inflammation with hyperplasia of the interstitial connective tissue are pathological hallmarks of muscular dystrophy. Inflammation of dystrophic muscle is dominated by macrophages and $\mathrm{T}$ lymphocytes that secrete pro-fibrotic cytokines. This causes a gradual development of fibrosis, which hinders muscle regeneration and ultimately leads to incomplete functional recovery [37]. Consequently, anti-inflammatory and immunosuppressive drugs such as corticosteroids and cyclosporine are beneficial for these conditions. However, weight gain and infections are common side effects of these pharmaceutical agents [38]. This provides a rationale for the development of therapeutics that target the molecular pathways involved in the fibrotic muscle pathology more specifically.

Transforming growth factor- $\beta$ (TGF- $\beta$ ), a cytokine that is released by inflammatory cells, has become a focus of attention in research on such signaling mechanisms [39]. Its expression is dramatically increased in muscular dystrophy [40]. Stimulation of muscle resident fibroblasts with this factor increases their collagen and fibronectin production, which results in increased interstitial fibrosis [41-43]. Furthermore, TGF- $\beta$ stimulates the differentiation of cultured myoblasts into a fibrogenic cell type [44]. This suggests that TGF- $\beta$ also drives satellite cells into this alternative lineage, which would ultimately deplete them from muscle and prevent efficient regeneration. Moreover, an increase in fibrogenic cells could further exacerbate muscle pathology by contributing to tissue fibrosis.

Inhibition of TGF- $\beta$ or its downstream effectors by large molecule ligand traps and antisense oligonucleotides are novel therapeutic approaches being explored today [45]. It is promising that some of these therapeutics have already been demonstrated to ameliorate muscular dystrophy in certain mouse models [46]. Interestingly, a recent study has demonstrated a dose-dependent requirement of cultured myoblasts for TGF- $\beta$. This suggests that specific concentrations of TGF- $\beta$ have permissive influences on satellite cells and it raises some concerns about the therapeutic window for inhibitors of this factor [47].

\section{Myostatin}

Myostatin has been demonstrated to be a powerful antagonist of muscle growth. Inhibition or genetic ablation of myostatin triggers dramatic increases in skeletal muscle mass across many different species [48]. The total number of muscle fibers per muscle is increased in myostatin knockout animals [49,50]. This is indicative of increased myogenic activity. Furthermore, the application of myostatin to cultured myoblasts prevents differentiation by suppressing MRFs. Conversely, silencing of myostatin in myoblast culture increases differentiation [51].

Muscle fibroblasts do express the myostatin receptor at high levels and its activation induces their proliferation and the secretion of fibrotic ECM proteins [52]. Myostatin inhibition could therefore be a means to improve regeneration of dystrophic muscle by reducing fibrosis while, at the same time, promoting the activation of satellite cells. Indeed, it has been demonstrated that myostatin deficiency or systemic application of inhibitory antibodies slows down the degeneration in dystrophic muscle of mdx mice [53].

The direct relevance of myostatin for satellite cells remains a matter of ongoing investigation. It has been reported that satellite cells of myostatin-null mice proliferate more in the resting state while the total number of satellite cells per muscle fiber increases. Furthermore, the regenerative potential of myostatin knockout muscle seems to be superior to the wild-type counterpart [51]. Intriguingly, a recent report rebutted that a myostatin deficiency is beneficial for $\mathrm{mdx}$ mice and also excluded a direct effect of myostatin on satellite cells [54]. This study challenges several previous reports and it will be interesting to follow the future debate on this topic.

A number of circulating factors that control myostatin activity have been discovered. Among these is follistatin, which can function as a potent myostatin antagonist. Overexpression of follistatin in mice causes muscle gains beyond myostatin inhibition, which suggests that it inhibits additional negative regulators of muscle growth and/or satellite cells [51]. Similar to lowering myostatin levels, delivery of follistatin to dystrophic mice reversed muscle pathology and improved strength [55].

Despite the controversy regarding which cell type mediates the effects of myostatin on muscle, antagonists that target this factor seem to be promising candidates for the treatment of several muscular disorders. Future studies will have to clarify the potential of myostatin inhibitors for direct therapeutic manipulation of satellite cells. 


\section{Insulin-like growth factor-1}

Insulin-like growth factor 1 (IGF-1) is either secreted by the liver as an endocrine hormone or produced locally by other tissues where it can act in a paracrine/autocrine fashion [56]. Exogenous IGF-1 or genetic overexpression results in increased muscle mass and enhanced regeneration in mice. Furthermore, IGF-1 levels are upregulated in regenerating muscle and hypertrophy induced by this factor not only involves an increase in protein synthesis but also augments the DNA content of muscle [51]. This evidence suggests that IGF-1 supports the mobilization of satellite cells for muscle regeneration.

After stimulation, muscle tissue expresses high levels of a splice variant of IGF-1, which is termed mechanogrowth factor (MGF) [57]. MGF promotes the proliferation and inhibits the differentiation of cultured myoblasts [58]. The main circulating isoform of IGF-1 has the same effect on proliferation but also facilitates differentiation [59-61]. This indicates that the paracrine/autocrine effects of MGF rather expand the satellite cell pool, while other IGF-1 variants are generally activating and allow differentiation. In agreement with this idea, addition of a synthetic MGF peptide increased the number of desminpositive myogenic cells isolated from healthy and diseased muscles [62]. However, because desmin is expressed by quiescent and activated satellite cells, MGF's potential for a sustained expansion of the satellite cell pool remains to be demonstrated [63]. Interestingly, mitotically active young muscle has been found to be most responsive to MGF, which argues against a direct effect on quiescent satellite cells [64].

In summary, there is evidence that both IGF-1 and MGF could be used to stimulate satellite cell function and proliferation under pathologic conditions. The first recombinant IGF-1 drugs have recently received US Food and Drug Administration (FDA) approval for the treatment of IGF-1 deficiency, and intense efforts for the expansion of its use in diseases such as sarcopenia, muscular dystrophy and amyotrophic lateral sclerosis are ongoing [65-67].

\section{Hepatocyte growth factor}

The expression of hepatocyte growth factor (HGF) spikes during the early phase of muscle regeneration and decreases subsequently during regeneration. HGF is sequestered in the ECM of skeletal muscle and released upon injury. This factor can stimulate the proliferation of cultured myoblasts while inhibiting differentiation [2]. In agreement with these findings, the application of recombinant HGF to injured muscle slows regeneration while increasing the number of activated satellite cells [68]. This suggests that HGF serves to activate quiescent satellite cells in the immediate phase after injury while blocking differentiation. Once the pool of proliferating satellite myogenic cells is sufficiently expanded in the later stages of muscle regeneration, HGF levels decline and differentiation is initiated. It remains to be determined whether treatment with HGF could be used to mobilize satellite cells in situations of inactivity, such as atrophy or cachexia.

It has been demonstrated that nitric oxide (NO) signaling may act upstream of HGF to modulate the activation state of satellite cells. NO seems to augment active HGF by triggering its release from the ECM through metalloproteinases [69]. Furthermore, increased levels of NO promotes regeneration of normal and dystrophic muscle $[70,71]$. The delivery of pharmaceutical compounds to increase NO signaling in diseased skeletal muscle is feasible and candidate drugs are currently being investigated [72].

\section{Fibroblast growth factor}

Several fibroblast growth factors (FGFs), particularly FGF-6 and FGF-2, have been demonstrated to induce the proliferation of cultured myoblasts while inhibiting their differentiation [2,73]. This indicates a role for these factors in the expansion of the satellite cell compartment. For instance, FGF-6 expression is muscle specific and is increased during regeneration [74]. However, results from studies of injury-challenged muscle in FGF-6deficient mice are controversial. Some reports demonstrated impaired regeneration whereas others could not confirm such effects $[74,75]$.

FGF2 is sequestered in the basement membrane surrounding developing and adult myotubes, and neutralizing antibodies against FGF2 seem to delay or prevent muscle regeneration in the immediate period after injury [76,77]. Furthermore, FGF2 appears to facilitate satellite cell divisions and muscle regeneration in dystrophic mice [78]. Moreover, the combined loss of the FGF2 and FGF6 genes increases the dystrophic pathology in the musculature of mdx mice, whereas the transgenic delivery of both factors to damaged muscle enhances regeneration $[79,80]$.

Therapeutic recombinant FGFs or biologically active derivatives could potentially be used to enhance the regenerative potential of muscle by increasing satellite cell number. However, further studies will have to clarify whether FGF treatment leads to the therapeutically desirable expansion of the satellite stem cell compartment as opposed to the presumably rather transient effects caused by an increase in satellite myogenic cells.

\section{Wnt}

Wnt proteins are secreted lipid-modified glycoproteins that act through Frizzled (Fzd) receptors. Mammals harbor 19 different $w n t$ and $10 \mathrm{fzd}$ genes. Historically, Wnt signaling has been divided into 'canonical' $\beta$-catenin-dependent 
and 'noncanonical' $\beta$-catenin-independent signaling pathways. More recently, this classification has been undermined and crosstalk between the canonical and noncanonical pathways has been described [81].

Given the variety of Wnts, it is not surprising that different species can excerpt both inhibitory and permissive effects on myogenic differentiation. For instance, some Wnt molecules facilitate myogenesis during regeneration while others have been demonstrated to drive the differentiation of satellite cells into a fibrotic lineage $[82,83]$.

It has been reported that a temporal switch from activation of the Notch pathway to increased Wnt3a signaling is required for myogenic lineage progression and consequently for effective muscle regeneration. The effects of Wnt3a and Notch signaling are mediated by the modulation of the common intracellular effector glycogen synthase kinase $3 \beta$ (GSK3 $\beta$ ) [84].

A recent study demonstrated that components of the noncanonical planar cell polarity $(\mathrm{PCP})$ pathway regulate the expansion of satellite stem cells during muscle regeneration in concert with Wnt7a. Wnt7a is expressed by muscle fibers in the immediate period after myocyte fusion. This suggests that Wnt7a release is a physiological means to expand the satellite stem cell pool after the initial phase of myogenesis. In agreement with this theory, muscle-injury-challenged Wnt7a-deficient mice display a reduced number of satellite stem cells. Furthermore, Wnt7a application enhances the regenerative capacity of skeletal muscle dramatically [8]. This demonstrates conclusively that an expansion of the satellite stem cell population is beneficial for skeletal muscle regeneration and suggests that manipulation of Wnt7a/ PCP signaling could be therapeutically relevant. Future studies will have to address the feasibility of recombinant Wnt7a, or mimetics of this factor, for the treatment of diseases that are accompanied by a disequilibrium in the satellite stem cell pool.

\section{Conclusions}

Knowledge about the factors that regulate satellite cell activity is not only crucial for their direct manipulation but will also foster the success of other approaches, such as stem cell therapy. Our understanding of the molecular mechanisms that control the specification and differentiation of satellite cells into a postmitotic muscle fiber has grown tremendously and a complexity far beyond expectations has emerged. In parallel, however, promising new starting points for the development of therapeutics have been discovered and it is only a matter of time until this translates into effective treatment options for degenerative muscular diseases.

\section{Abbreviations}

$\mathrm{ECM}=$ extracellular matrix; FGF = fibroblast growth factor; Fzd = Frizzled; $\mathrm{HGF}=$ hepatocyte growth factor; MGF = mechano-growth factor; $\mathrm{MRF}=$ myogenic regulatory factor; $\mathrm{Myf}=$ myogenic factor; $\mathrm{MyoD}=$ myoblast determination protein; $\mathrm{NO}=$ nitric oxide; $\mathrm{PCP}=$ planar cell polarity; $\mathrm{TGF}=$ transforming growth factor.

\section{Competing interests}

The authors declare that they have no competing interests.

\section{Acknowledgements}

Studies from the laboratory of MAR were supported by grants from the Canadian Institutes of Health Research, Muscular Dystrophy Association, National Institutes of Health, Howard Hughes Medical Institute, Canadian Stem Cell Network, and Canada Research Chair Program. MAR holds the Canada Research Chair in Molecular Genetics and is an International Research Scholar of the Howard Hughes Medical Institute. CFB is supported by the Swiss National Science Foundation. We thank Feodor Price and Yu Xin Wang for critical reading of the manuscript.

\section{Author details}

'The Sprott Centre for Stem Cell Research, Regenerative Medicine Program, Ottawa Health Research Institute, Ottawa, Ontario K1H 8L6, Canada. ${ }^{2}$ Department of Cellular and Molecular Medicine, Faculty of Medicine, University of Ottawa, Ottawa, Ontario K1H 8M5, Canada

Published: 26 August 2010

\section{References}

1. Sambasivan R, Tajbakhsh S: Skeletal muscle stem cell birth and properties. Semin Cell Dev Biol 2007, 18:870-882.

2. Charge $S B$, Rudnicki MA: Cellular and molecular regulation of muscle regeneration. Physiol Rev 2004, 84:209-238.

3. Tajbakhsh S: Skeletal muscle stem cells in developmental versus regenerative myogenesis. J Intern Med 2009, 266:372-389.

4. Marcell TJ: Sarcopenia: causes, consequences, and preventions. J Gerontol A Biol Sci Med Sci 2003, 58:M911-916.

5. Mauro A: Satellite cell of skeletal muscle fibers. J Biophys Biochem Cytol 1961, 9:493-495.

6. Rudnicki MA, Le Grand F, McKinnell I, Kuang S: The molecular regulation of muscle stem cell function. Cold Spring Harb Symp Quant Biol 2008, 73:323-331.

7. Kuang S, Kuroda K, Le Grand F, Rudnicki MA: Asymmetric self-renewal and commitment of satellite stem cells in muscle. Cell 2007, 129:999-1010.

8. Le Grand F, Jones AE, Seale V, Scime A, Rudnicki MA: Wnt7a activates the planar cell polarity pathway to drive the symmetric expansion of satellite stem cells. Cell Stem Cell 2009, 4:535-547.

9. Gossler A, Hrabe de Angelis M: Somitogenesis. Curr Top Dev Biol 1998, 38:225-287.

10. Kalcheim C, Ben-Yair R: Cell rearrangements during development of the somite and its derivatives. Curr Opin Genet Dev 2005, 15:371-380.

11. Gros J, Manceau M, Thome V, Marcelle C: A common somitic origin for embryonic muscle progenitors and satellite cells. Nature 2005, 435:954-958.

12. Relaix F, Rocancourt D, Mansouri A, Buckingham M: A Pax3/Pax7-dependent population of skeletal muscle progenitor cells. Nature 2005, 435:948-953.

13. Kassar-Duchossoy L, Giacone E, Gayraud-Morel B, Jory A, Gomes D, Tajbakhsh S: Pax3/Pax7 mark a novel population of primitive myogenic cells during development. Genes Dev 2005, 19:1426-1431.

14. Schienda J, Engleka KA, Jun S, Hansen MS, Epstein JA, Tabin CJ, Kunkel LM, Kardon G: Somitic origin of limb muscle satellite and side population cells. Proc Natl Acad Sci U SA 2006, 103:945-950.

15. Buckingham M, Bajard L, Chang T, Daubas P, Hadchouel J, Meilhac S Montarras D, Rocancourt D, Relaix F: The formation of skeletal muscle: from somite to limb. J Anat 2003, 202:59-68.

16. Schultz E: Satellite cell proliferative compartments in growing skeletal muscles. Dev Biol 1996, 175:84-94.

17. Ben-Yair R, Kalcheim C: Lineage analysis of the avian dermomyotome sheet reveals the existence of single cells with both dermal and muscle progenitor fates. Development 2005, 132:689-701.

18. Kuang S, Rudnicki MA: The emerging biology of satellite cells and their therapeutic potential. Trends Mol Med 2008, 14:82-91.

19. Kuang S, Gillespie MA, Rudnicki MA: Niche regulation of muscle satellite cell self-renewal and differentiation. Cell Stem Cell 2008, 2:22-31. 
20. Zhang K, Sha J, Harter ML: MyoD: A new function: ensuring "DNA licensing". Cell Cycle 2010, 9.

21. Scadden DT: The stem-cell niche as an entity of action. Nature 2006, 441:1075-1079.

22. Christov C, Chretien F, Abou-Khalil R, Bassez G, Vallet G, Authier FJ, Bassaglia Y, Shinin V, Tajbakhsh S, Chazaud B, Gherardi RK: Muscle satellite cells and endothelial cells: close neighbors and privileged partners. Mol Biol Cell 2007, 18:1397-1409.

23. Molgo J, Colasantei C, Adams DS, Jaimovich E: IP3 receptors and Ca2+ signals in adult skeletal muscle satellite cells in situ. Biol Res 2004, 37:635-639.

24. Tatsumi R, Liu X, Pulido A, Morales M, Sakata T, Dial S, Hattori A, Ikeuchi Y, Allen RE: Satellite cell activation in stretched skeletal muscle and the role of nitric oxide and hepatocyte growth factor. Am J Physiol Cell Physiol 2006, 290:C1487-1494

25. Calve S, Odelberg SJ, Simon HG: A transitional extracellular matrix instructs cell behavior during muscle regeneration. Dev Biol 2010, 344:259-271.

26. Podleski TR, Greenberg I, Schlessinger J, Yamada KM: Fibronectin delays the fusion of L6 myoblasts. Exp Cell Res 1979, 122:317-326.

27. Foster RF, Thompson JM, Kaufman SJ: A laminin substrate promotes myogenesis in rat skeletal muscle cultures: analysis of replication and development using antidesmin and anti-BrdUrd monoclonal antibodies. Dev Biol 1987, 122:11-20.

28. Bentzinger CF, Barzaghi P, Lin S, Ruegg MA: Overexpression of mini-agrin in skeletal muscle increases muscle integrity and regenerative capacity in laminin-alpha2-deficient mice. Faseb J 2005, 19:934-942.

29. Ohtake Y, Tojo H, Seiki M: Multifunctional roles of MT1-MMP in myofiber formation and morphostatic maintenance of skeletal muscle. J Cell Sci 2006, 119:3822-3832.

30. Shefer G, Van de Mark DP, Richardson JB, Yablonka-Reuveni Z: Satellite-cell pool size does matter: defining the myogenic potency of aging skeletal muscle. Dev Biol 2006, 294:50-66.

31. Carlson BM, Faulkner JA: Muscle transplantation between young and old rats: age of host determines recovery. Am J Physiol 1989, 256:C1262-1266.

32. Zacks SI, Sheff MF: Age-related impeded regeneration of mouse minced anterior tibial muscle. Muscle Nerve 1982, 5:152-161.

33. Conboy IM, Conboy MJ, Wagers AJ, Girma ER, Weissman IL, Rando TA: Rejuvenation of aged progenitor cells by exposure to a young systemic environment. Nature 2005, 433:760-764

34. Farini A, Razini P, Erratico S, Torrente Y, Meregalli M: Cell based therapy for Duchenne muscular dystrophy. I Cell Physiol 2009, 221:526-534.

35. Rader RA: (Re)defining biopharmaceutical. Nat Biotechnol 2008, 26:743-751.

36. Wong G: Biotech scientists bank on big pharma's biologics push. Nat Biotechnol 2009, 27:293-295.

37. Emery AE: The muscular dystrophies. Lancet 2002, 359:687-695

38. Radley HG, De Luca A, Lynch GS, Grounds MD: Duchenne muscular dystrophy: focus on pharmaceutical and nutritional interventions. Int $J$ Biochem Cell Biol 2007, 39:469-477.

39. Dietz HC: TGF-beta in the pathogenesis and prevention of disease: a matter of aneurysmic proportions. J Clin Invest, 120:403-407.

40. Serrano AL, Munoz-Canoves P: Regulation and dysregulation of fibrosis in skeletal muscle. Exp Cell Res 2010 [Epub ahead of print]

41. Grande JP, Melder DC, Zinsmeister AR: Modulation of collagen gene expression by cytokines: stimulatory effect of transforming growth factorbeta1, with divergent effects of epidermal growth factor and tumor necrosis factor-alpha on collagen type I and collagen type IV. J Lab Clin Med 1997, 130:476-486.

42. Ignotz RA, Massague J: Transforming growth factor-beta stimulates the expression of fibronectin and collagen and their incorporation into the extracellular matrix. J Biol Chem 1986, 261:4337-4345.

43. LeRoy EC, Trojanowska MI, Smith EA: Cytokines and human fibrosis. Eur Cytokine Netw 1990, 1:215-219.

44. Li Y, Foster W, Deasy BM, Chan Y, Prisk V, Tang Y, Cummins J, Huard J: Transforming growth factor-beta1 induces the differentiation of myogenic cells into fibrotic cells in injured skeletal muscle: a key event in muscle fibrogenesis. Am J Pathol 2004, 164:1007-1019.

45. Korpal $M$, Kang $Y$ : Targeting the transforming growth factor-beta signalling pathway in metastatic cancer. Eur $J$ Cancer, 46:1232-1240.

46. Cohn RD, van Erp C, Habashi JP, Soleimani AA, Klein EC, Lisi MT, Gamradt M, ap Rhys CM, Holm TM, Loeys BL, Ramirez F, Judge DP, Ward CW, Dietz HC: Angiotensin II type 1 receptor blockade attenuates TGF-beta-induced failure of muscle regeneration in multiple myopathic states. Nat Med 2007, 13:204-210.

47. Carlson ME, Conboy MJ, Hsu M, Barchas L, Jeong J, Agrawal A, Mikels AJ, Agrawal S, Schaffer DV, Conboy IM: Relative roles of TGF-beta1 and Wnt in the systemic regulation and aging of satellite cell responses. Aging Cell 2009, 8:676-689.

48. Lee SJ: Regulation of muscle mass by myostatin. Annu Rev Cell Dev Biol 2004, 20:61-86.

49. McPherron AC, Lawler AM, Lee SJ: Regulation of skeletal muscle mass in mice by a new TGF-beta superfamily member. Nature 1997, 387:83-90.

50. Kambadur R, Sharma M, Smith TP, Bass JJ: Mutations in myostatin (GDF8) in double-muscled Belgian Blue and Piedmontese cattle. Genome Res 1997, 7:910-916.

51. Cassano M, Quattrocelli M, Crippa S, Perini I, Ronzoni F, Sampaolesi M: Cellular mechanisms and local progenitor activation to regulate skeletal muscle mass. J Muscle Res Cell Motil 2009, 30:243-253.

52. Li ZB, Kollias HD, Wagner KR: Myostatin directly regulates skeletal muscle fibrosis. J Biol Chem 2008, 283:19371-19378.

53. Bogdanovich S, Krag TO, Barton ER, Morris LD, Whittemore LA, Ahima RS, Khurana TS: Functional improvement of dystrophic muscle by myostatin blockade. Nature 2002, 420:418-421.

54. Amthor H, Otto A, Vulin A, Rochat A, Dumonceaux J, Garcia L, Mouisel E, Hourdé C, Macharia R, Friedrichs M, Relaix F, Zammit PS, Matsakas A, Patel K, Partridge T: Muscle hypertrophy driven by myostatin blockade does not require stem/precursor-cell activity. Proc Natl Acad Sci U S A 2009, 106:7479-7484.

55. Haidet AM, Rizo L, Handy C, Umapathi P, Eagle A, Shilling C, Boue D, Martin PT, Sahenk Z, Mendell JR, Kaspar BK: Long-term enhancement of skeletal muscle mass and strength by single gene administration of myostatin inhibitors. Proc Natl Acad Sci U S A 2008, 105:4318-4322.

56. Dai Z, Wu F Yeung EW, LiY. IGF-IEc expression, regulation and biological function in different tissues. Growth Horm IGF Res 2010, 20:275-281.

57. McKoy G, Ashley W, Mander J, Yang SY, Williams N, Russell B, Goldspink G: Expression of insulin growth factor-1 splice variants and structural genes in rabbit skeletal muscle induced by stretch and stimulation. J Physio/ 1999, 516:583-592

58. Yang SY, Goldspink G: Different roles of the IGF-I Ec peptide (MGF) and mature IGF-I in myoblast proliferation and differentiation. FEBS Lett 2002, 522:156-160.

59. Allen RE, Boxhorn LK: Regulation of skeletal muscle satellite cell proliferation and differentiation by transforming growth factor-beta, insulin-like growth factor I, and fibroblast growth factor. J Cell Physiol 1989, 138:311-315.

60. Doumit ME, Cook DR, Merkel RA: Testosterone up-regulates androgen receptors and decreases differentiation of porcine myogenic satellite cells in vitro. Endocrinology 1996, 137:1385-1394.

61. Adi S, Bin-Abbas B, Wu NY, Rosenthal SM: Early stimulation and late inhibition of extracellular signal-regulated kinase $1 / 2$ phosphorylation by IGF-I: a potential mechanism mediating the switch in IGF-I action on skeletal muscle cell differentiation. Endocrinology 2002, 143:511-516.

62. Ates K, Yang SY, Orrell RW, Sinanan AC, Simons P, Solomon A, Beech S, Goldspink G, Lewis MP: The IGF-I splice variant MGF increases progenitor cells in ALS, dystrophic, and normal muscle. FEBS Lett 2007, 581:2727-2732.

63. Day K, Shefer G, Richardson JB, Enikolopov G, Yablonka-Reuveni Z: NestinGFP reporter expression defines the quiescent state of skeletal muscle satellite cells. Dev Biol 2007, 304:246-259.

64. Barton ER: Viral expression of insulin-like growth factor-l isoforms promotes different responses in skeletal muscle. J Appl Physiol 2006, 100:1778-1784.

65. Scicchitano BM, Rizzuto E, Musaro A: Counteracting muscle wasting in aging and neuromuscular diseases: the critical role of IGF-1. Aging (Albany NY) 2009, 1:451-457.

66. Norman P: Mecasermin Tercica. Curr Opin Investig Drugs 2006, 7:371-380

67. Kemp SF: Mecasermin rinfabate. Drugs Today (Barc) 2007, 43:149-155.

68. Miller KJ, Thaloor D, Matteson S, Pavlath GK: Hepatocyte growth factor affects satellite cell activation and differentiation in regenerating skeletal muscle. Am J Physiol Cell Physiol 2000, 278:C174-181.

69. Tatsumi R: Mechano-biology of skeletal muscle hypertrophy and regeneration: possible mechanism of stretch-induced activation of resident myogenic stem cells. Anim Sci J, 81:11-20.

70. Wehling M, Spencer MJ, Tidball JG: A nitric oxide synthase transgene 
ameliorates muscular dystrophy in mdx mice. J Cell Bio/ 2001, 155:123-131.

71. Wang G, Burczynski FJ, Hasinoff BB, Zhang K, Lu Q, Anderson JE:

Development of a nitric oxide-releasing analogue of the muscle relaxant guaifenesin for skeletal muscle satellite cell myogenesis. Mol Pharm 2009, 6:895-904.

72. Tidball JG, Wehling-Henricks M: Evolving therapeutic strategies for Duchenne muscular dystrophy: targeting downstream events. Pediatr Res 2004, 56:831-841.

73. Allen RE, Dodson MV, Luiten LS: Regulation of skeletal muscle satellite cell proliferation by bovine pituitary fibroblast growth factor. Exp Cell Res 1984, 152:154-160.

74. Floss T, Arnold HH, Braun T: A role for FGF-6 in skeletal muscle regeneration. Genes Dev 1997, 11:2040-2051.

75. Fiore F, Sebille A, Birnbaum D: Skeletal muscle regeneration is not impaired in Fgf6 -/- mutant mice. Biochem Biophys Res Commun 2000, 272:138-143.

76. Cornelison DD, Filla MS, Stanley HM, Rapraeger AC, Olwin BB: Syndecan-3 and syndecan- 4 specifically mark skeletal muscle satellite cells and are implicated in satellite cell maintenance and muscle regeneration. Dev Biol 2001, 239:79-94

77. Lefaucheur JP, Sebille A: Muscle regeneration following injury can be modified in vivo by immune neutralization of basic fibroblast growth factor, transforming growth factor beta 1 or insulin-like growth factor I. J Neuroimmunol 1995, 57:85-91.

78. Lefaucheur JP, Sebille A: Basic fibroblast growth factor promotes in vivo muscle regeneration in murine muscular dystrophy. Neurosci Lett 1995,
202:121-124.

79. Neuhaus P, Oustanina S, Loch T, Kruger M, Bober E, Dono R, Zeller R, Braun T: Reduced mobility of fibroblast growth factor (FGF)-deficient myoblasts might contribute to dystrophic changes in the musculature of FGF2/ FGF6/mdx triple-mutant mice. Mol Cell Biol 2003, 23:6037-6048.

80. Doukas J, Blease K, Craig D, Ma C, Chandler LA, Sosnowski BA, Pierce GF: Delivery of FGF genes to wound repair cells enhances arteriogenesis and myogenesis in skeletal muscle. Mol Ther 2002, 5:517-527.

81. van Amerongen R, Nusse R: Towards an integrated view of Wnt signaling in development. Development 2009, 136:3205-3214

82. Brack AS, Conboy MJ, Roy S, Lee M, Kuo CJ, Keller C, Rando TA: Increased Wnt signaling during aging alters muscle stem cell fate and increases fibrosis. Science 2007, 317:807-810.

83. Polesskaya A, Seale P, Rudnicki MA: Wnt signaling induces the myogenic specification of resident CD45+ adult stem cells during muscle regeneration. Cell 2003, 113:841-852.

84. Brack AS, Conboy IM, Conboy MJ, Shen J, Rando TA: A temporal switch from notch to Wnt signaling in muscle stem cells is necessary for normal adult myogenesis. Cell Stem Cell 2008, 2:50-59.

doi:10.1186/scrt27

Cite this article as: Bentzinger CF, et al:: Extrinsic regulation of satellite cell specification. Stem Cell Research \& Therapy 2010, 1:27. 